Original Research Article

\title{
Comparative study between Direct Microscopy and Indirect Haemagglutination Methods Used in Diagnosis of Urinary Schistosomiasis
}

\author{
Mohammed Elzubair Abdallah ${ }^{1 *}$, Musab Hussin Mohamed $^{1}$, Elamin Abdelkarim Elamin ${ }^{1}$ \\ ${ }^{T}$ Department of Parasitology \& Medical Entomology, Faculty of Medical Laboratory Sciences, Alneelain University, \\ Khartoum-Sudan
}

*Corresponding Author

Mohammed Elzubair Abdallah

\author{
Article History \\ Received: 08.02.2021 \\ Accepted: 26.02.2021 \\ Published: 05.03.2021
}

\begin{abstract}
Background: Schistosomiasis is one of the world's most prevalent parasitic infections, with at least 200 million people infected and about 700 million at risk in Africa, Asia, and South America. Although five species of waterborne trematodes in the genus Schistosoma are capable of causing human infection, the most important are $S$. haematobium \& Schistosoma mansoni and the majority of cases occur in sub-Saharan Africa. Methods: A_comparative study aimed to compare between indirect-hemagglutination assay and Golden Stander Method which used for diagnosis of Schistosoma haematobium. Total of 73.0 samples were collected from people located in two villages in the areas of Sudan endemic with Schistosoma haematobium. The samples were analyzed by the centrifuged parasitological examination and indirecthemagglutination assay (IHA). Result: Statistical analysis of the results showed that the sensitivity value of the IHA test was $95.8 \%$ and specificity was $4.1 \%$. Conclusion: A search for a good diagnostic test that can be applied in field situations in Sudan should be given high priority.
\end{abstract}

Keywords: Urinary schistosomiasis, direct microscopy, indirect haemagglutination, Patients, Khartoum, Sudan.

\section{INTRODUCTION}

Schistosomiasis is one of the world's most prevalent parasitic infections, with at least 200 million people infected and about 700 million at risk in Africa, Asia, and South America [1]. Although five species of waterborne trematodes in the genus Schistosoma are capable of causing human infection, the most important are Schistosoma mansoni and S. haematobium, and the majority of cases occur in sub-Saharan Africa [2]. Schistosomiasis is a parasitic trematodiasis caused by several species of the genus Schistosoma, of which S. mansoni, S. japonicum, S. mekongi, and $S$. haematobium are of public health importance. These worms live in the veins around the intestine or urinary bladder. Eggs are released in the stool or urine of the host and hatch in water [1]. Humans are usually infected when they come into contact with contaminated fresh water such as collecting water, washing, bathing, playing, fishing, or cultivating crops. In general, children, women, fishermen, and farmers are the high risk groups in schistosomiasis, also other people can infect in the irrigation channels or rivers and suffer from hematuria and anemia, enlargement of the liver and spleen, and growth retardation [3, 4]. Due to the geographical distribution of schistosomiasis and the affected populations, schistosomiasis is listed as a neglected tropical disease and a neglected infection of poverty. Apart from this, imported schistosomiasis has been recognized as an emerging clinical problem in countries where the disease is not endemic [5-7, 18]. The infection affects expatriates and immigrants but also travelers, especially in association with adventure and ecotourism $[5-7,18]$.

During early stages, schistosoma infections might cause severe manifestations, such as Katayama fever, schistosomal myeloradiculopathy, and pneumonitis $[9,10,8,12]$. However, up to $50 \%$ of newly infected patients remain asymptomatic [13-15]. Independent of the initial presentation, untreated schistosomiasis might lead to complications such as obstructive uropathies, hepatic fibrosis, or granulomatous cerebral lesions [7, 17, 18]. To prevent those late manifestations, any case of schistosomiasis should be detected and treated [18].

Copyright (C) 2021 The Author(s): This is an open-access article distributed under the terms of the Creative Commons Attribution 4.0 International License (CC BY-NC 4.0) which permits unrestricted use, distribution, and reproduction in any medium for non-commercial use provided the original author and source are credited. 
Like the case for other parasitic infections, the diagnostic approach to schistosomiasis depends on the epidemiological situation. In endemic settings, parasitological examinations are the mainstay of diagnosis. Serological examinations, such as screening for antischistosomal antibodies, are of limited use for the diagnosis of active infection, as large parts of the population may carry antibodies due to past infections [2].

The diagnosis of imported schistosomiasis in individuals from countries where the disease is not endemic bears other challenges. First, those patients seem to be more prone to acute manifestations, which occur during early stages of infection and sometimes during the pre-patent period [2]. Furthermore, exposure to cercarial larvae is usually limited, resulting in infections with low parasite loads $[19,8,11]$. Therefore, direct parasitological methods often fail ${ }^{[19]}$. For this patient group, serological tests detecting antischistosomal antibodies are an important diagnostic tool [20-22]. Although the "seronegative window" has to be considered in very early infections [5, 8, 23].

Over the last decades, various serological methods have been developed to detect antibodies against Schistosoma antigens. Different techniques have been applied, including indirect immunofluorescent-antibody tests (IFATs), indirect hemagglutination assays (IHAs), and enzyme-linked immunosorbent assays (ELISAs) using different antigens, such as crude or purified adult worm antigen (AWA), soluble egg antigen (SEA), and cercarial antigen (CA) preparations [24-36, 21, 37, 16, 22].

Nevertheless, very few studies have addressed the value of serological assays for diagnosis of schistosomiasis in individuals from areas where the disease is not endemic and who are carrying light and/or recently acquired infections; most of those describe single in-house assays and are limited by small sample numbers [39, 40]. Only one study analyzed a commercial test together with an in-house assay [16].

\section{Material ANd Method}

This is a comparative experimental study carried out to compare between two methods used for diagnosis of schistosomiasis. The samples were collected from 73 patients confirmed having schistosomiasis by urine samples which were analyzed using Microscope method from area of Om usher (jebelaulia) governorate southern Khartoum state.

Inclusion Criteria: (Resident in Um usher village, Jebel Aulia governorate, Khartoum state - Known patient with urinary schistosomiasis).

Exclusion Criteria: (Resident outside Om usher village, Jebel Aulia governorate, Khartoum state- People Free from urinary schistosomiasis). Principle of method called.

Shistosomiasisfumouze: Is based on indirect heamagltuination sensitized red blood cells are composed of sheep red cell coated with shistosoma mansoni antigen.

Specific serum antibodies are revealed by an agglutination of the sensitized red blood cells a reddish-brown film can be observed in the absence of specific antibodies these red blood cells deposit forming a ring in well bottom. The unsensitized red blood cells ensure the reaction specificity and the elimination of interference due to natural anti sheep antibodies (For ssmanhetero antibodies, infectious mononucleosis antibodies). The reaction was performed in U-micro plate. The test procedure is easy and rapid. The result is obtained in 2 hours. Data was analyzed using SPSS version 25. The results expressed as frequency and percentage. Chi-square test was used to compare the difference between IHA and Golden standard methods. Sensitivity was defined as the proportion of patients with a positive test result among those with proven infection. Specificity was calculated as the proportion of patients with a negative test result among samples of the control group.

\section{RESULT}

A total of 73 patients male (10-40 years) from Om ushar in the areas endemic with Schistosoma hematobium were analyzed by the parasitological examination and hemagglutination assay (IHA).

Table-1: Frequency and percentage of indirect-hemagglutination assay and Golden Standard Method for diagnosis of Schistosoma $(\mathbf{n}=73)$

\begin{tabular}{|l|l|l|}
\hline Methods & +Ve F (\%) & -Ve F (\%) \\
\hline IHA & $70(96 \%)$ & $3(4 \%)$ \\
\hline GSM & $73(100 \%)$ & $0(0.0 \%)$ \\
\hline \multicolumn{3}{|c|}{ F $=$ frequency }
\end{tabular}


The result showed in Table-1 determine that the frequency of IHA was (4\%) and specificity was (4.1) while the frequency of golden standard method $(0 \%)$

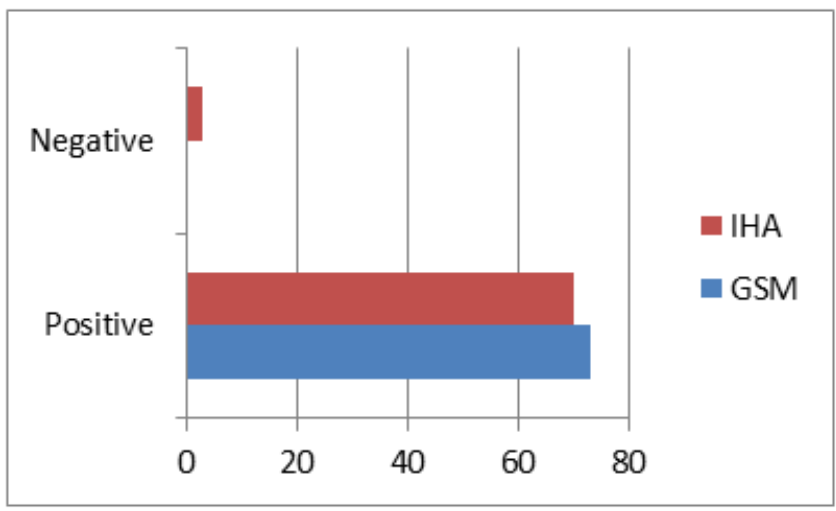

Fig-1: Compare positivity of IHA against GSM for diagnosis of Schistosoma haematobium $(\mathrm{n}=73)$

Table-2: Shows Sensitivity and positive predictive value (PPV) of IHA assay in compare to GSM for diagnosis of Schistosoma haematobium

\begin{tabular}{|l|l|l|}
\hline Method & Sensitivity \% & PPV \\
\hline IHA & 94.87 & $95.89 \%$ \\
\hline
\end{tabular}

The result showed in Table-2 determine that the sensitivity of IHA was (94.87\%) and have a PPV of (95.89\%).

\section{DISCUSSION}

In areas of endemicity, where past Schistosoma infections, high Schistosoma loads, and polyparasitism are frequent, serological testing that have high specificity to avoid false-positive results. In such settings, and combination of serological tests (screening followed by confirmation) has been widely used in endemic areas because it is more sensitive than parasitological diagnosis and antibodies are easier to detect than antigens [42]. In this study, we used three circulating antibody detection methods (IHA) tests which are the most widely used assays in People's Republic of china [42]. Our study highlights the usefulness within this patient group, serology has two aims: (i) to diagnose symptomatic infections and (ii) to screen asymptomatic individuals with reported freshwater exposure in areas where schistosomiasis is endemic. A known obstacle to serodiagnosis of acute or recent schistosome infection is the prolonged seronegative window period. Antibody production in newly infected individuals usually starts 4 to 7 weeks after infection, and although the majority of patients exhibit seroconversion within 3 months $[10,13,14]$, prolonged seronegative window periods of up to 6 months have been described $[9,10]$.

This study showed that commercially available IHA test is sensitive and tests for the serodiagnosis of schistosomiasis in endemic tropic area. Among our serum samples, IHA method revealed sensitivity similar to that detected by Tom van Gool et al., [16] in the Netherlands when they got 94\% sensitivity when they investigated patient sera infected by Schistosoma mansoni and Schistosoma haematobium. This suggests that almost all patients had seroconvert at the time that the samples were taken. [12] In contrast our result showed higher sensitivity to detect Schistosoma antibodies when it's compared to similar study done by Annie Sulahian et al., [43] in France when they evaluated sensitivity of IHA method in a total of 48 sera sample from patients with parasitological confirmed cases of schistosomiasis out of them 35 were positive giving sensitivity equal to $72.9 \%$. Also ours study result is higher than the result obtained by Hans-Friedemann Kinkel et al., [44] in Germany that showed $73 \%$ sensitivity when they investigated 37 patient with confirmed, this Cleary state that our study is high and these differences might have been caused by differences in the serum panel that was used in these studies however this highlights the variability of test sensitivity in different clinical settings and the difficulty in comparing diagnostic test performances obtained in different studies.

Some limitations of the present study are that it included sera only from patients with egg-proven schistosomiasis. Also since the prevalent period of schistosomiasis is 4 to 6 weeks, our gold standard had a negative bias for very early infections and a probable positive bias toward larger parasite burdens, since parasitological methods are more sensitive to larger worm loads [8]. Still, parasitological proof is the accepted diagnostic gold standard [9]. A multicenter study including large sample size and comparing other serological and advanced molecular technique is needed to overcome most of the above-mentioned limitations. 


\section{CONCLUSION}

This study concluded that the IHA test was useful tool for the diagnosis schistosomiasis in endemics area and had good sensitivity values to be used as screening and diagnostic tool.

\section{ACKNOWLEDGMENTS}

We would like to thank the participant from him blood and urine sample were collected.

\section{Ethical Consideration}

Informed consent was written and signed by each participant following explanation of the study and sample collection procedure. The participants' information was kept confidential.

\section{Strength}

The study focusing in important public health problems located in agricultural areas causing social and economic problems.

\section{REFERENCES}

1. World Health Organization. (2010). Schistosomiasis. Fact sheet no. 115. World Health Organization, Geneva, Switzerland: http://www.who.int/mediacentre/factsheets/fs115/en/.

2. Gryseels, B., Polman, K., Clerinx, J., \& Kestens, L. (2006). Human schistosomiasis. The Lancet, 368(9541), $1106-1118$.

3. Gryseels, B. (2012). Schistosomiasis. Infect Dis Clin North Am, 26: 383-397.

4. Stothard, J. R., Sousa-Figueiredo, J. C., Betson, M., Bustinduy, A., \& Reinhard-Rupp, J. (2013). Schistosomiasis in African infants and preschool children: let them now be treated!. Trends in parasitology, 29(4), 197-205.

5. Corachan, M. (2002). Schistosomiasis and international travel. Clinical infectious diseases, 35(4), 446-450.

6. Grobusch, M. P., Mühlberger, N., Jelinek, T., Bisoffi, Z., Corachan, M., Harms, G., .. \& Hellgren, U. (2003). Imported schistosomiasis in Europe: sentinel surveillance data from TropNetEurop. Journal of travel medicine, 10(3), 164-169.

7. Hatz, C. F. (2005). Schistosomiasis: an underestimated problem in industrialized countries?. J Travel Med. 12:1-2.

8. Jauréguiberry, S., Paris, L., \& Caumes, E. (2010). Acute schistosomiasis, a diagnostic and therapeutic challenge. Clinical microbiology and infection, 16(3), 225-231.

9. Bottieau, E., Clerinx, J., De Vega, M. R., Van den Enden, E., Colebunders, R., Van Esbroeck, M., ... \& Van den Ende, J. (2006). Imported Katayama fever: clinical and biological features at presentation and during treatment. Journal of Infection, 52(5), 339-345.

10. Carod-Artal, F. J. (2008). Neurological complications of Schistosoma infection. Transactions of the Royal Society of Tropical Medicine and Hygiene, 102(2), 107-116.

11. Lambertucci, J. R. (2010). Acute schistosomiasis mansoni: revisited and reconsidered. Memórias do Instituto Oswaldo Cruz, 105(4), 422-435.

12. Ross, A. G., Vickers, D., Olds, G. R., Shah, S. M., \& McManus, D. P. (2007). Katayama syndrome. The Lancet infectious diseases, 7(3), 218-224.

13. Meltzer, E., Artom, G., Marva, E., Assous, M. V., Rahav, G., \& Schwartz, E. (2006). Schistosomiasis among travelers: new aspects of an old disease. Emerging infectious diseases, 12(11), 1696-1700.

14. Nicolls, D. J., Weld, L. H., Schwartz, E., Reed, C., Von Sonnenburg, F., Freedman, D. O., \& Kozarsky, P. E. (2008). Characteristics of schistosomiasis in travelers reported to the GeoSentinel Surveillance Network 1997-2008. The American journal of tropical medicine and hygiene, 79(5), 729-734.

15. Whitty, C. J., Mabey, D. C., Armstrong, M., Wright, S. G., \& Chiodini, P. L. (2000). Presentation and outcome of 1107 cases of schistosomiasis from Africa diagnosed in a non-endemic country. Transactions of the Royal Society of Tropical Medicine and Hygiene, 94(5), 531-534.

16. Van Gool, T., Vetter, H., Vervoort, T., Doenhoff, M. J., Wetsteyn, J., \& Overbosch, D. (2002). Serodiagnosis of imported schistosomiasis by a combination of a commercial indirect hemagglutination test with Schistosoma mansoni adult worm antigens and an enzyme-linked immunosorbent assay with S. mansoni egg antigens. Journal of Clinical Microbiology, 40(9), 3432-3437.

17. Meltzer, E., Artom, G., Marva, E., Assous, M. V., Rahav, G., \& Schwartz, E. (2006). Schistosomiasis among travelers: new aspects of an old disease. Emerging infectious diseases, 12(11), 1696-1700.

18. Nicolls, D. J., Weld, L. H., Schwartz, E., Reed, C., Von Sonnenburg, F., Freedman, D. O., \& Kozarsky, P. E. (2008). Characteristics of schistosomiasis in travelers reported to the GeoSentinel Surveillance Network 1997-2008. The American journal of tropical medicine and hygiene, 79(5), 729-734.

19. Doenhoff, M. J., Chiodini, P. L., \& Hamilton, J. V. (2004). Specific and sensitive diagnosis of schistosome infection: can it be done with antibodies?. Trends in parasitology, 20(1), 35-39.

20. Jelinek, T., Nothdurft, H. D., \& Löscher, T. (1996). Schistosomiasis in travelers and expatriates. Journal of Travel Medicine, 3(3), 160-164.

21. Tarp, B., Black, F. T., \& Petersen, E. (2000). The immunofluorescence antibody test (IFAT) for the diagnosis of schistosomiasis used in a non-endemic area. Tropical Medicine \& International Health, 5(3), 185-191. 
22. Whitty, C. J., Carroll, B., Armstrong, M., Dow, C., Snashall, D., Marshall, T., \& Chiodini, P. L. (2000). Utility of history, examination and laboratory tests in screening those returning to Europe from the tropics for parasitic infection. Tropical Medicine \& International Health, 5(11), 818-823.

23. Visser, L. G., Polderman, A. M., \& Stuiver, P. C. (1995). Outbreak of schistosomiasis among travelers returning from Mali, West Africa. Clinical infectious diseases, 20(2), 280-285.

24. Ambroise-Thomas, P., \& Grillot, R. (1980). Indirect hemagglutination in the diagnosis of bilharziasis. Comparison with indirect immunofluorescence in the study of 3624 human serums. Bulletin de la Societe de Pathologie Exotique et de ses Filiales, 73(3), 277-288.

25. Ambroise-Thomas, P., Loizzo, T., \& Desgeorges, P. T. (1981, September). Human schistosomiasis due to Schistosoma mansoni, S. haematobium and S. japonicum. Serological diagnosis by ELISA, immunofluorescence and indirect hemagglutination. In Annales de la Societe belge de medecine tropicale (Vol. 61, No. 3, pp. 379-392).

26. Bierman, W. F., Wetsteyn, J. C., \& Van Gool, T. (2005). Presentation and diagnosis of imported schistosomiasis: relevance of eosinophilia, microscopy for ova, and serology. Journal of Travel Medicine, 12(1), 9-13.

27. Chand, M. A., Chiodini, P. L., \& Doenhoff, M. J. (2010). Development of a new assay for the diagnosis of schistosomiasis, using cercarial antigens. Transactions of the Royal Society of Tropical Medicine and Hygiene, 104(4), 255-258.

28. Deelder, A. M., \& Kornelis, D. (1981). Immunodiagnosis of recently acquired Schistosoma mansoni infection. A comparison of various immunological techniques. Tropical and geographical medicine, 33(1), 36-41.

29. El-Ganayni, G. A., \& Youssef, M. E. (1992). Evaluation of adult Schistosoma mansoni and cercarial antigens in serodiagnosis of schistosomiasis using IHAT and ELISA. Journal of the Egyptian Society of Parasitology, 22(2), 555560.

30. Evengård, B. (1990). Diagnostic and clinical aspects of schistosomiasis in 182 patients treated at a Swedish ward for tropical diseases during a 10-year period. Scandinavian journal of infectious diseases, 22(5), 585-594.

31. Feldmeier, H., \& Büttner, D. W. (1983). Immunodiagnosis of Schistosomiasis haematobium and Schistosomiasis mansoni in man application of crude extracts from adult worms and cercariae in the IHA and the ELISA. Zentralblatt für Bakteriologie, Mikrobiologie und Hygiene. 1. Abt. Originale. A, Medizinische Mikrobiologie, Infektionskrankheiten und Parasitologie, 255(2-3), 413-421.

32. Hamilton, J. V., Klinkert, M., \& Doenhoff, M. J. (1999). Diagnosis of schistosomiasis: antibody detection, with notes on parasitological and antigen detection methods. Parasitology, 117(7), 41-57.

33. Hancock, K., \& Tsang, V. C. (1986). Development and optimization of the FAST-ELISA for detecting antibodies to Schistosoma mansoni. Journal of immunological methods, 92(2), 167-176.

34. Mott, K. E., \& Dixon, H. (1982). Collaborative study on antigens for immunodiagnosis of schistosomiasis. Bulletin of the World Health Organization, 60(5), 729-753.

35. Nash, T. E., Ottesen, E. A., \& Cheever, A. W. (1978). Antibody response to a polysaccharide antigen present in the schistosome gut. The American Journal of Tropical Medicine and Hygiene, 27(5), 944-950.

36. Nash, T. E., Ottesen, E. A., \& Cheever, A. W. (1978). Antibody response to a polysaccharide antigen present in the schistosome gut. II. Modulation of antibody response. The American Journal of Tropical Medicine and Hygiene, 27(5), 944-950.

37. Valli, L. C. P., Kanamura, H. Y., Da Silva, R. M., Silva, M. I. P., Vellosa, S. A., \& Garcia, E. T. (1997). Efficacy of an enzyme-linked immunosorbent assay in the diagnosis of and serologic distinction between acute and chronic Schistosoma mansoni infection. The American journal of tropical medicine and hygiene, 57(3), 358-362.

38. Enk, M. J., Lima, A. C. L., Drummond, S. C., Schall, V. T., \& Coelho, P. M. Z. (2008). The effect of the number of stool samples on the observed prevalence and the infection intensity with Schistosoma mansoni among a population in an area of low transmission. Acta tropica, 108(2-3), 222-228.

39. Evengård, B. (1990). Diagnostic and clinical aspects of schistosomiasis in 182 patients treated at a Swedish ward for tropical diseases during a 10-year period. Scandinavian journal of infectious diseases, 22(5), 585-594.

40. Tosswill, J. H., \& Ridley, D. S. (1986). An evaluation of the ELISA for schistosomiasis in a hospital population. Transactions of the Royal Society of Tropical Medicine and Hygiene, 80(3), 435-438.

41. Tsang, V. C., \& Wilkins, P. P. (1991). Immunodiagnosis of schistosomiasis. Screen with FAST-ELISA and confirm with immunoblot. Clinics in laboratory medicine, 11(4), 1029-1039.

42. Cai, Y. C., Xu, J. F., Steinmann, P., Chen, S. H., Chu, Y. H., Tian, L. G., ... \& Chen, J. X. (2014). Field comparison of circulating antibody assays versus circulating antigen assays for the detection of schistosomiasis japonica in endemic areas of China. Parasites \& vectors, 7(1), 1-8.

43. Sulahian, A., Garin, Y. J. F., Izri, A., Verret, C., Delaunay, P., van Gool, T., \& Derouin, F. (2005). Development and evaluation of a Western blot kit for diagnosis of schistosomiasis. Clinical and diagnostic laboratory immunology, 12(4), 548-551.

44. Kinkel, H. F., Dittrich, S., Bäumer, B., \& Weitzel, T. (2012). Evaluation of eight serological tests for diagnosis of imported schistosomiasis. Clinical and Vaccine Immunology, 19(6), 948-953.

Citation: Elzubair Abdallah et al (2021). Comparative study between Direct Microscopy and Indirect Haemagglutination Methods Used in Diagnosis of Urinary Schistosomiasis. South Asian Res J Bio Appl Biosci, 3(2), 20-24. 